\title{
Wear-resisting properties of multilayer coated carbide blades under different technological conditions of turning of heat-resistant steel
}

\author{
Vyacheslav Pchelkin ${ }^{1, *}$, and Tatyana Duyun ${ }^{1}$ \\ ${ }^{1}$ Belgorod State Technological University named after V.G. Shukhov, 46, Kostyukova Street, Russia, \\ Belgorod, 308012
}

\begin{abstract}
Experimented results of wear-resisting properties of carbide blades with multilayer wear-resistance coatings, obtained by different processes: chemical vapor deposition and spraying by condensation from vapour (gas) phase while turning of corrosion -resistant heat-resistant steel 08X18H10T are presented.
\end{abstract}

\section{Articulation of issue}

Corrosion - resistant heat-resistant steel 08X18H10T is widely used for the manufacturing of welded equipment, heat exchangers, pipes and other parts, operated in high aggressive environments. [1]. The given steel class is classified as hard-to-machine one as per its physical and mechanical properties [2]. The main problems during machining of hard-tomachine materials such as corrosion - resistant heat-resistant steel are high cutting temperature and severe wear of cutting instrument, that is why the increase of metal-cutting tool durability period by means of use of reasonable cutting parameters is an important scientific task.

\section{Analysis of the sources of literature}

Characteristic properties of wear of carbide blades while high-speed machining are considered in the paper [3]. Durability of hardening coatings of metal-cutting tool under

\footnotetext{
${ }^{*}$ Corresponding author: pvm0106@mail.ru
} 
conditions of impact loads is considered in details in the paper [4]. By the analysis of the sources of literature it was determined, that cutting technological conditions (presence of impact loads, absence of cooling) have a significant impact on wear-resisting properties of multilayer coated carbide blades.

\section{Work objective}

The objective of the work is an investigational study of wear-resisting properties of multilayer coated carbide blades under different technological conditions of turning of heatresistant steel: with an impact and without cooling.

\section{Work results}

A full factorial experiment was conducted for three technological parameters (stepover of cutter, cutting speed and depth) under technological conditions of turning with an impact and cooling and turning without an impact and without cooling. Two types of carbide blades with the coating, obtained by different processes, were used:

- WNMG080408-MMKMM253 with the coating CVD (ChemicalVaporDeposition), obtained by chemical vapor deposition, KMM253 - an alloy with an innovative technology of application of ultra-fine-grained coating on tight gradient base.

- WNMG080408-MMKMG203 with the coating PVD (PhysicalVapourDeposition), obtained by spraying of condensation from vapour (gas) phase.

Empirical models of wear-resisting properties depending on speed, stepover of cutter and cutting depth with natural factor scores were obtained: expression (1) - turning with an impact for KMM253 alloy, expression (2) - turning with an impact for KMG203 alloy:

$$
\begin{aligned}
& T(V, s, t)=1,418 \cdot V^{-0,519} \cdot s^{-2,1} \cdot t^{-0,358} \\
& T(V, s, t)=234 \cdot V^{-1,19} \cdot s^{-1,404} \cdot t^{-0,447}
\end{aligned}
$$

where $V$ - cutting speed; $s$-stepover of cutter; $t$ - cutting depth.

Figure 1 presents dependence of tool durability on the speed and stepover of cutter during turning with an impact of corrosion - resistant heat-resistant steel by the alloy of cutting blade KMM253, and figure 2 presents similar dependencies during turning with KMG203 alloy. 

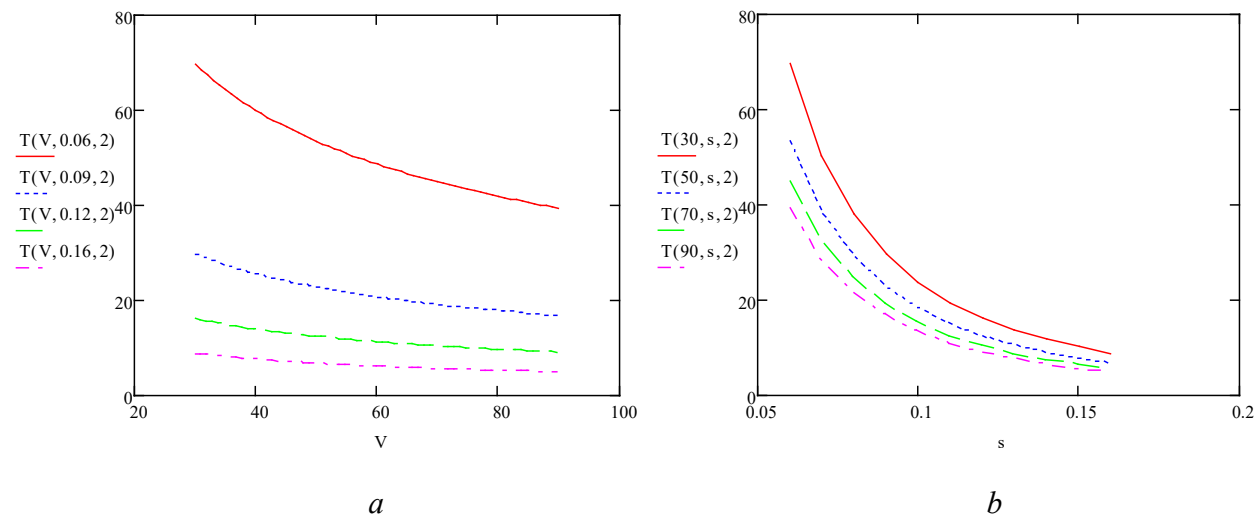

Fig. 1. Influence of process parameters on tool durability from KMM253 alloy during turning with an impact: a - dependence on cutting speed with the stepovers of $0,06 \mathrm{~mm} / \mathrm{rev} ., 0,09 \mathrm{~mm} / \mathrm{rev} ., 0,12$ $\mathrm{mm} / \mathrm{rev}$., $0,16 \mathrm{~mm} / \mathrm{rev}$; $b$ - dependence on stepover with the speed of $30 \mathrm{~m} / \mathrm{min}, 50 \mathrm{~m} / \mathrm{min}, 70$ $\mathrm{m} / \mathrm{min}, 90 \mathrm{~m} / \mathrm{min}$.

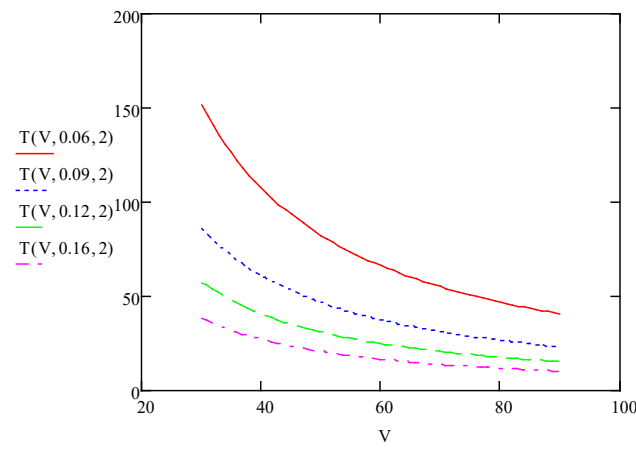

$a$

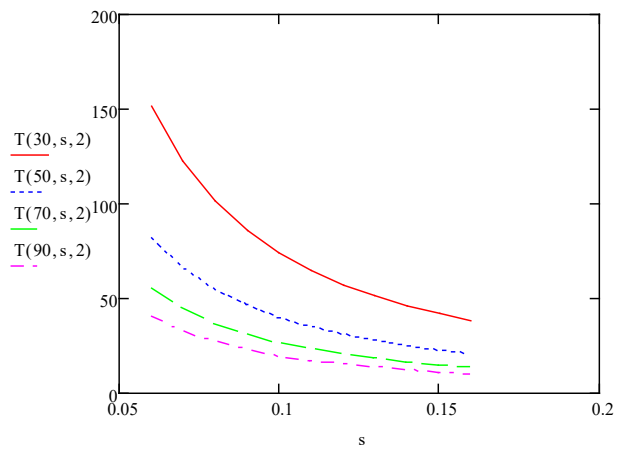

$b$

Fig. 2. Influence of process parameters on tool durability from KMG203 alloy during turning with an impact: $a$-dependence on cutting speed with the stepovers of $0,06 \mathrm{~mm} / \mathrm{rev} ., 0,09 \mathrm{~mm} / \mathrm{rev} ., 0,12$ $\mathrm{mm} / \mathrm{rev}$., $0,16 \mathrm{~mm} / \mathrm{rev}$; $\mathrm{b}$ - dependence on stepover with the speed of $30 \mathrm{~m} / \mathrm{min}, 50 \mathrm{~m} / \mathrm{min}, 70$ $\mathrm{m} / \mathrm{min}, 90 \mathrm{~m} / \mathrm{min}$.

Expressions (3) and (4) describe durability during turning without an impact and without cooling correspondingly by the blades from KMM253 alloy and KMG203 alloy:

$$
\begin{gathered}
T(V, s, t)=130,4 \cdot V^{-0,647} \cdot s^{-0,43} \cdot t^{-0,395} \\
T(V, s, t)=179,5 \cdot V^{-0,775} \cdot s^{-0,36} \cdot t^{-0,373}
\end{gathered}
$$


Figures 3 and 4 present dependence of tool durability on the speed and stepover of cutter during turning without an impact correspondingly by the alloy of the cutting blade KMM253 and KMG203 alloy.

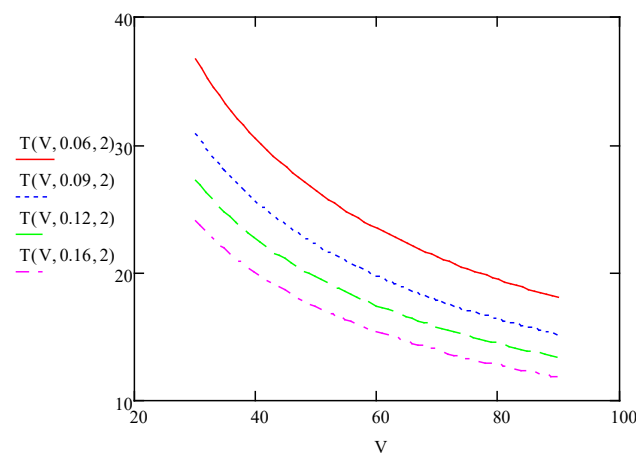

$a$

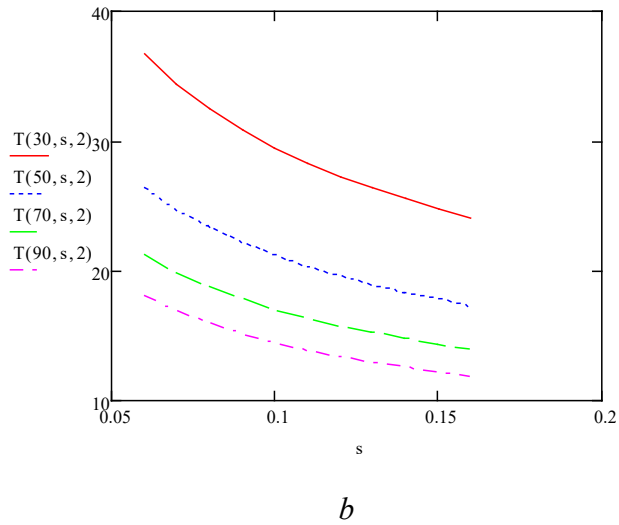

Fig. 3. Influence of process parameters on tool durability from KMM 253 alloy during turning without an impact: $a$-dependence on cutting speed with the stepovers of $0,06 \mathrm{~mm} / \mathrm{rev} ., 0,09 \mathrm{~mm} / \mathrm{rev} ., 0,12$ $\mathrm{mm} / \mathrm{rev}$., $0,16 \mathrm{~mm} / \mathrm{rev}$.; $b$ - dependence on stepover with the speed of $30 \mathrm{~m} / \mathrm{min}, 50 \mathrm{~m} / \mathrm{min}, 70$ $\mathrm{m} / \mathrm{min}, 90 \mathrm{~m} / \mathrm{min}$.

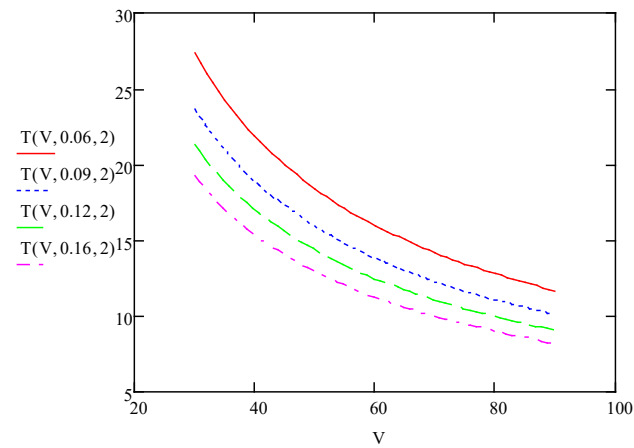

$a$

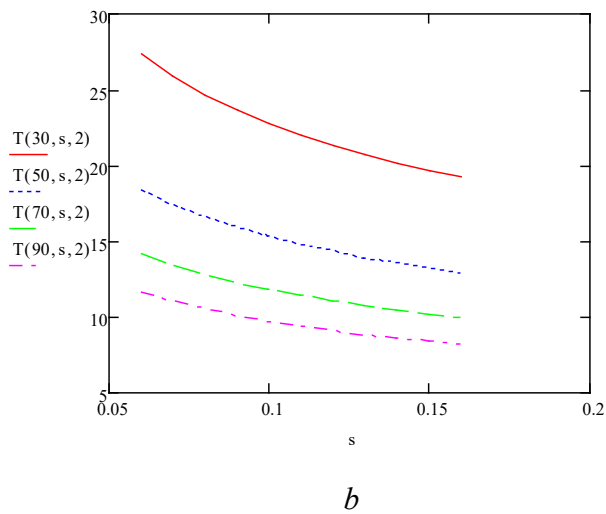

Fig. 4. Influence of process parameters on tool durability from KMG203 alloy during turning without an impact: $a$-dependence on cutting speed with the stepovers of $0,06 \mathrm{~mm} / \mathrm{rev} ., 0,09 \mathrm{~mm} / \mathrm{rev} ., 0,12$ $\mathrm{mm} / \mathrm{rev}$., $0,16 \mathrm{~mm} / \mathrm{rev}$; $b$ - dependence on stepover with the speed of $30 \mathrm{~m} / \mathrm{min}, 50 \mathrm{~m} / \mathrm{min}, 70$ $\mathrm{m} / \mathrm{min}, 90 \mathrm{~m} / \mathrm{min}$.

Use of the electronic microscope MIRA3 TESCAN helped to identify wear pattern of the rear surface of cutting edges (fig. 5). An alloy with double-layer CVD coating has a 
strongly marked wear and the breakage of the cutting edge on the base material. Cutting edge of an alloy with PVD coating was not deformed, the wear of the rear surface is located only in the area of contact marking while cutting.

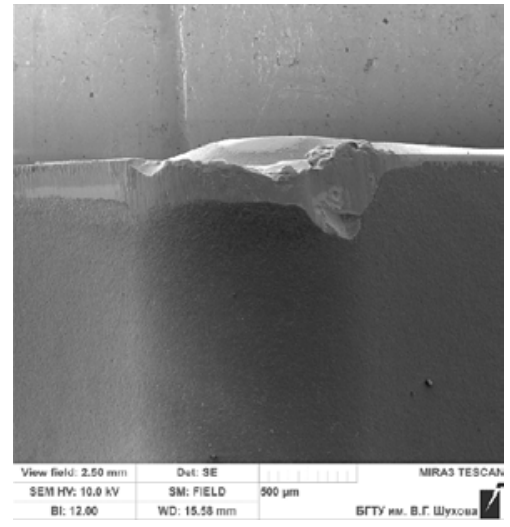

$a$

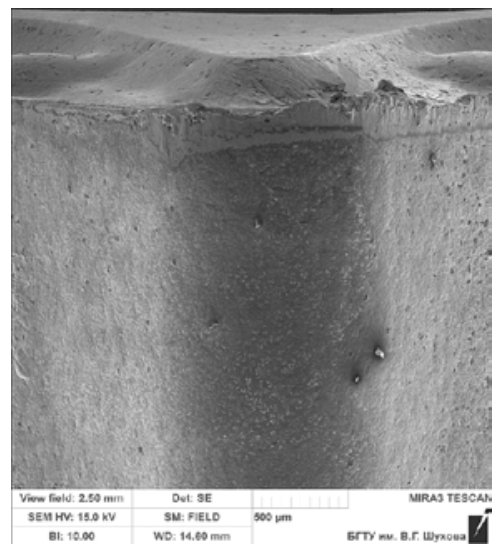

$c$

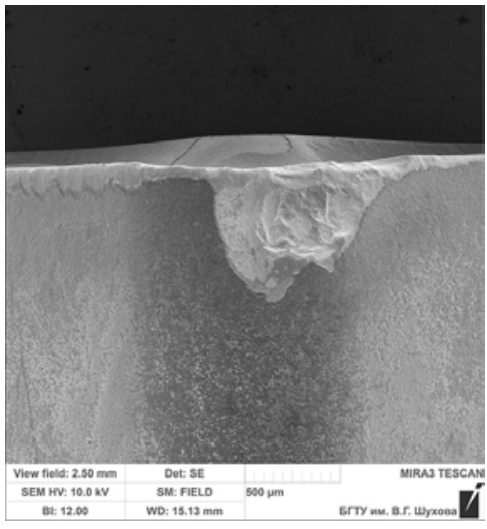

$b$

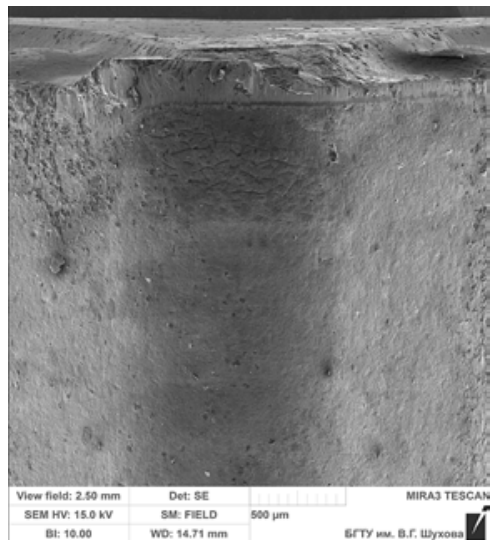

$d$

Fig. 5. Wear pattern of cutting blade: a - turning with an impact by KMM253 alloy with CVD coating; $\mathrm{b}$ - turning with an impact by KMG203 alloy with PVD coating; $\mathrm{c}$ - turning without an impact by KMM253 alloy with CVD coating; $d$ - turning without an impact by KMG203 alloy with PVD coating.

Both coatings have a wearing of the coating in the area of chip-breaker projection and formation of grooves on the side surface of the edge, which is not involved in cutting. Such a wear is caused by chip removal from processing area and does not affect tool wear 
resistant characteristics. Strong cleavages of the cutting edge are seen while turning with an impact (fig.5, $a, b$ ), turning without an impact is characterized by uniform wear (fig.5, $c, d$ ).

The functions of the electronic microscope, enabling to have magnified image with the scale reading $0,2 \mathrm{mcm}$, were used for the microstructural examination and structural changes caused by heat and load impacts. Such a magnifying enables to examine layers of surface layer and adhesion between them (fig. 6, 7).

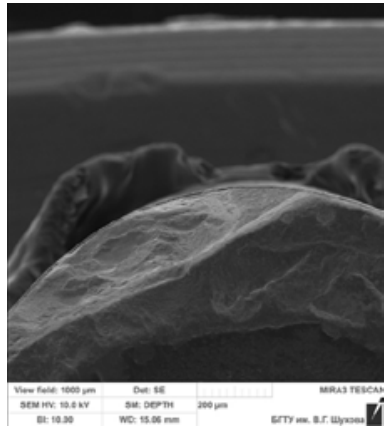

$a$

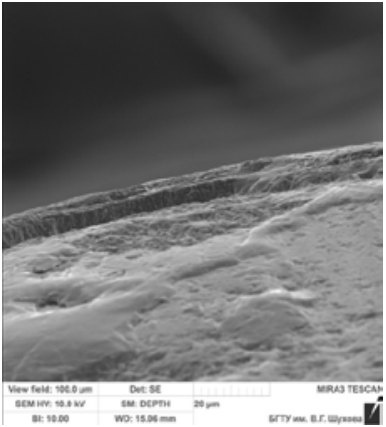

$b$

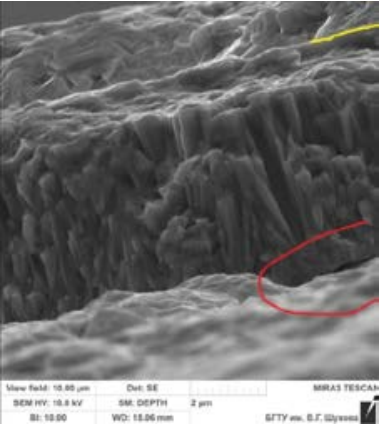

C

Fig. 6. Layers of the coating of KMM 253 alloy with CVD technology, turning with an impact: a magnifying up to scale reading $20 \mathrm{mcm}$; b - magnifying up to scale reading $2 \mathrm{mcm}, \mathrm{c}$ - magnifying up to scale reading $0,2 \mathrm{mcm}$.

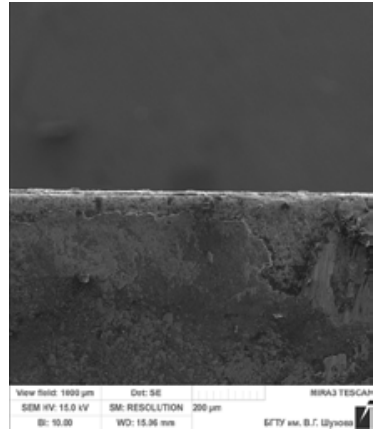

$a$

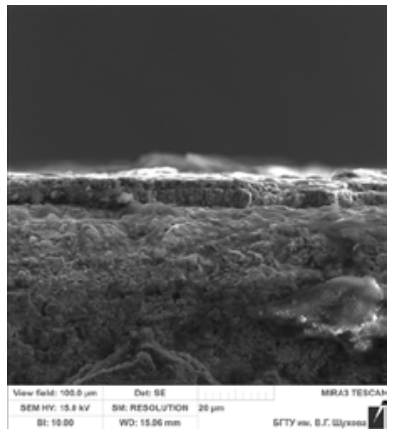

b

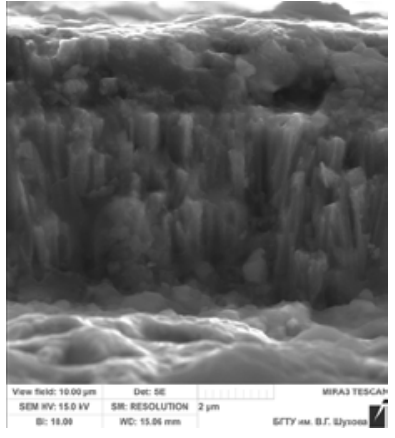

$c$

Fig. 7. Layers of the coating of KMM253 alloy with CVD technology, tuning without an impact: a magnifying up to scale reading $20 \mathrm{mcm}$; b- magnifying up to scale reading $2 \mathrm{mcm}, \mathrm{c}$ - magnifying up to scale reading $0,2 \mathrm{mcm}$.

Borders of the layers are clearly seen in Fig. 6 with the magnifying up to $0,2 \mathrm{mcm}$ in the structure of KMM253 coating with CVD technology, upper $\mathrm{AL}_{2} \mathrm{O}_{3}$ and lower TiN layers of the coating have different characteristic structure, breakdown of adhesion with the base 
material of the blade is observed. Under conditions of longitudinal turning without load impacts (fig. 7) two layers are seen in the wear area, no breakdown of adhesion.

\section{Conclusions}

Developed empirical models of tool durability while turning by KMM253 alloy and KMG203 alloy under different technological processing conditions allow to reasonably determine process parameters, ensuring the established durability parameters, predict the duration of tool operational capability, optimize process parameters with the aim of increase in efficiency and cost reduction of parts manufacturing. Microscopic examination proved the effect of impact loads on the adhesion of protective coating of carbide blades.

The article is prepared in the framework of development of the Base University on the basis of BSTU named after V.G. Shukhov.

\section{References}

1. V. Sorokin. Alloys and steel grades guide / V. G Sorokin, A. V. Volosnikova, S. A Vyatkin. - M.: Machine industry, 1989. $-640 \mathrm{p}$.

2. GOST 5632-72 High-alloy steels and corrosion-proof, heat-resisting and heat treated alloys. Grades. M.: IPC Publishing House of Standards, 1997. 64p.

3. V. Pchelkin Education, science, production T.1, BSTU named after V.G. Shukhov. C.1703-1707 (2015).

4. V. Pchelkin, T. Duyun Bulletin of BSTU named after V.G. Shukhov 6. C. 128-134. (2017). 